\title{
Flow over evaporator in electrotechnical box
}

\author{
Tomáš Puchor ${ }^{1, *}$, Richard Lenhard ${ }^{1}$ \\ ${ }^{1}$ University of Žilina, Department of Power Engineering, Univerzitná 1, 01026 Žilina, Slovakia
}

\begin{abstract}
The article focus on heat flow generated by heat points over evaporator in eletrotechnical box. The evaporator consists of horizontal pipes supplemented with vertical ribs to enlarge the heat exchanger surface. This ribs were changed as porous zone for simulation process. The evaporator is located in a hermetically sealed electrotechnical box. Observes the spread of heat in the porous materials and air over evaporator and space inside the electrical box.
\end{abstract}

\section{Introduction}

Electronic components inside all devices are producing heat. Some of them are producing more heat than an others and can cause failure. This heat need to be carried out to make device work properly. This work focus for heat distribution over evaporator inside electro technical box by visualisation with CFD simulation using ANSYS workbench. Model consist from model of box and inside it is evaporator with ribs. This ribs are a computational load and are replaced by a porous model. Optimized model with porous zone is better for simulation and less time consuming process. This simulation can be used to optimize a more complicated model in the future and provides a preview of the problem of solving the exchanger with ribs by using a porous model.

\section{Model of evaporator}

On Figure 1 is shown model of evaporator with ribs and model with porous zone. The design of the cooling device was based on a comparison of the current work on the refrigeration equipment for electronic components and by space inside electrotechnical box. This evaporator consists of horizontal tubes supplemented by vertical ribs to increase the heat exchange surface [1]. Evaporator is placed inside box at back wall with $30 \mathrm{~mm}$ offset. At Table 1 are dimension parameter of evaporator with ribs. Because simulation process with ribs is very time consuming, the model with porous part was chosen.

\footnotetext{
*Corresponding author: tomas.puchor@,fstroj.uniza.sk
} 
Table 1. Dimensions of exchanger.

\begin{tabular}{|c|c|c|c|}
\hline Fins & & Pipes & \\
\hline Quantity [pcs] & 265 & Quantity [pcs] & 33 \\
\hline Dimensions [mm] & $50 \times 1600$ & Diameter [mm] & 15 \\
\hline Thickness [mm] & 0.25 & Length [mm] & 660 \\
\hline Distance $[\mathrm{mm}]$ & 2.25 & Material & copper \\
\hline Material & aluminium & & \\
\hline
\end{tabular}

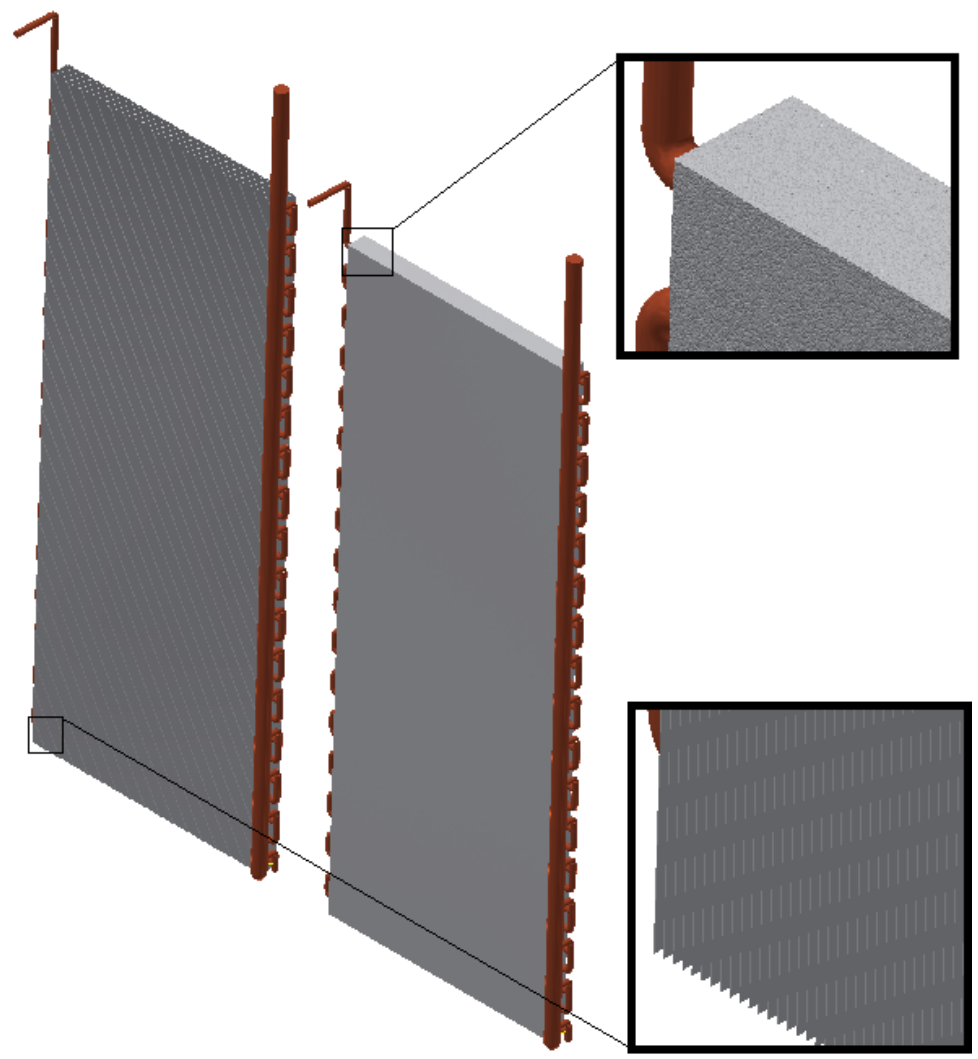

Fig. 1. Model of evaporator with porous material (right) and with ribs (left) and detail.

\section{Meshing}

Meshing setup was simple. Set up for generating mesh using ANSYS CFD meshing was to get the basic result with standard quality. Size function was set to curvature with fine relevance center. Initial size seed was set for active assembly. Smoothing, transition and span angle center was set as low, slow and fine. Curvature normal angle was set from default to $15^{\circ}$ to get better mesh. All size setup was left to default. Part of generated mesh can be seen on Figure 2 . 


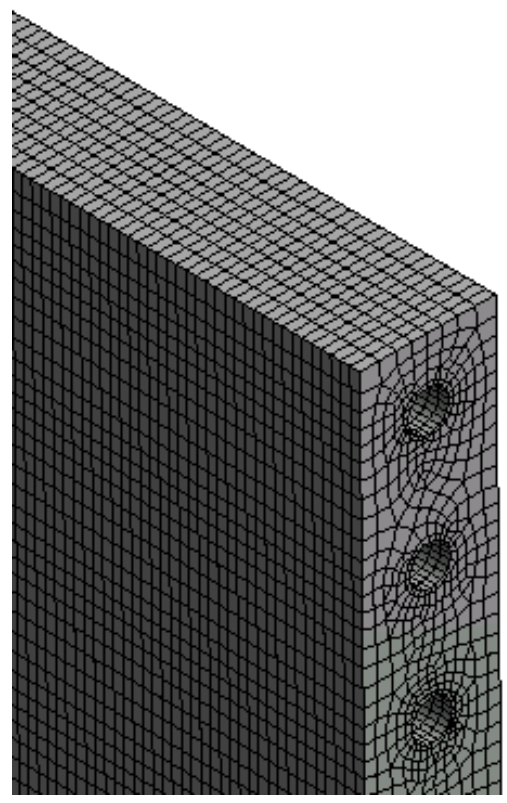

Fig. 2. Meshed model.

\section{Pressure drop over porous evaporator}

To correctly determine boundary conditions for successful simulation and result, the porous zone was needed to calculate. A porous zone is used in cases where a flow has to be defined, for example, through filters and heat exchangers. Instead of a 3D detailed model, the component is set on a simplified spatial model or porosity on the surface. As material with porosity was chosen air. Porosity is a ratio between solid volume and air volume to the total examined volume. It was calculated based on ribs and air space. The resulting porosity was $98 \%$. Consequently, it was necessary to determine the coefficients of porosity [2]. These coefficients were calculated on the basis of the pressure loss in the ribbed exchanger for both cases of air distribution over evaporator with different velocity as seen in Table 2 .

Table 2. Pressure loss.

\begin{tabular}{|c|c|c|}
\hline \multirow{2}{*}{ Velocity [m/s] } & \multicolumn{2}{|c|}{ Case } \\
\cline { 2 - 3 } & $\mathbf{1}$ & $\mathbf{2}$ \\
\cline { 2 - 3 } & \multicolumn{2}{|c|}{ Pressure [Pa] } \\
\hline 2.5 & 113.96 & 12.98 \\
\hline 3.5 & 160.13 & 22.30 \\
\hline 4.5 & 206.63 & 33.39 \\
\hline 5.5 & 253.45 & 46.34 \\
\hline 6.5 & 300.59 & 61.06 \\
\hline
\end{tabular}


The space between the two ribs was used for the calculation. However, for the accuracy of the calculation, pressures from three intercostal spaces were used [2]. The procedure for deriving the loss coefficients of the porous zone is given by.

$$
\Delta p=-\left(\frac{\mu}{\alpha} \cdot v+C_{2} \cdot \frac{1}{2} \cdot \rho \cdot v^{2}\right) t
$$

Where $\mu$ is kinematic viscosity of air, $\rho$ is air density, $t$ is thickness of porous media, $\alpha$ is the permeability and $C_{2}$ is the inertial resistance factor.

From the data obtained from the airflow simulation in the intersection space, a course and then a trend equation are created [3].

$$
y=-7.2416 x^{2}+94.55 x
$$

Coefficients in the trend equation (Figure 3) are used in the following formulas and the loss constants for the porous medium are calculated $[4,5]$.

$$
\begin{aligned}
& -7.2416=C_{2} \cdot 1 / 2 \cdot \rho \cdot t \\
& 64.689=\mu / \alpha . t
\end{aligned}
$$

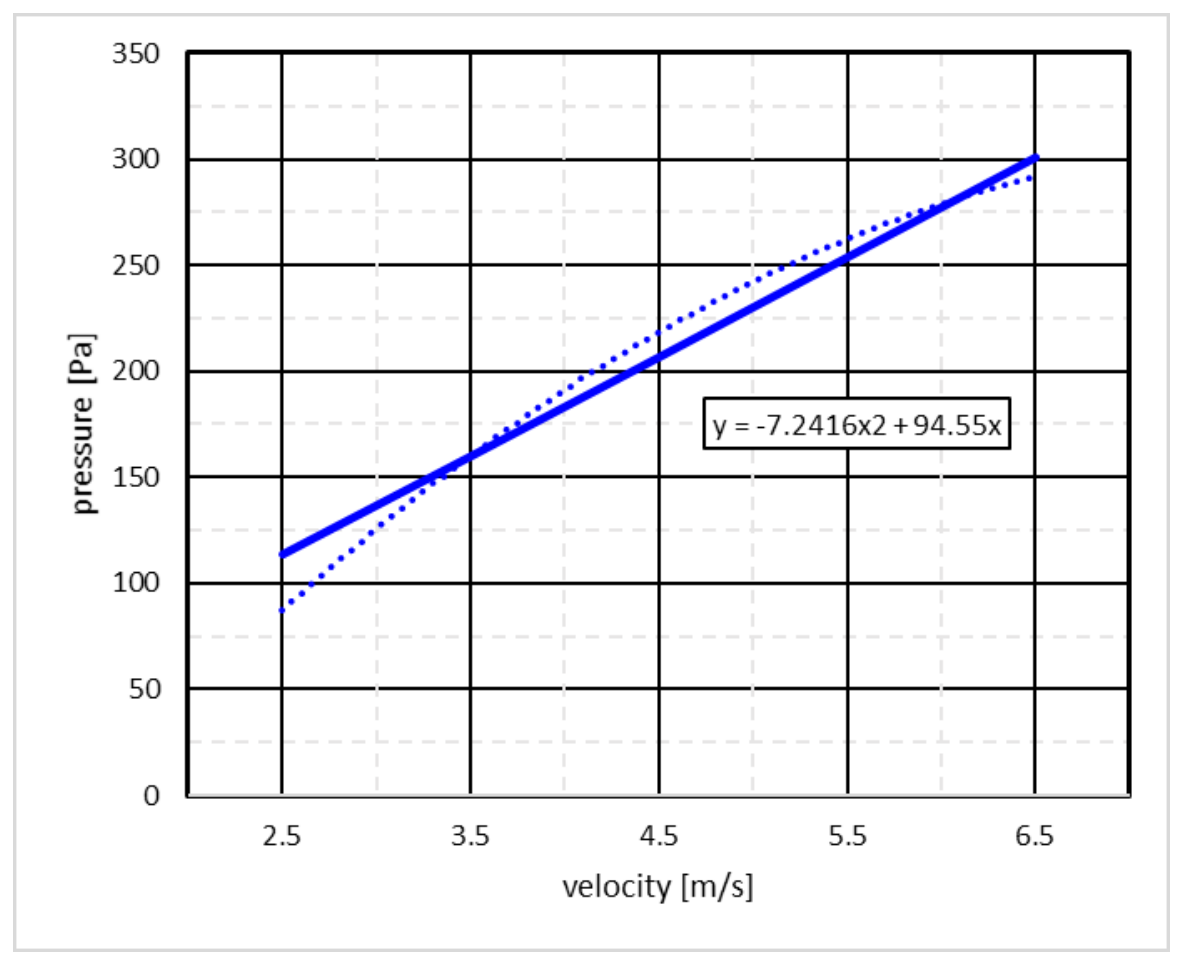

Fig. 3. The process of pressure loss through a porous environment.

The loss coefficients was then used for setting up the porous parameters in cell zone conditions for material air as seen in Table 3 . 
Table 3. Resulting loss coefficients.

\begin{tabular}{|l|c|c|}
\hline \multicolumn{3}{|c|}{ Relative Velocity Resistance Formulation } \\
\hline \multicolumn{2}{|c|}{ Viscous Resistance (Inverse absolute Permeability) } \\
\hline Diretion-1 $\left[1 / \mathrm{m}^{2}\right]$ & $1.056779 \mathrm{e}+08$ & \multirow{2}{*}{ constant } \\
\cline { 1 - 2 } Diretion-2 $\left[1 / \mathrm{m}^{2}\right]$ & $1.056779 \mathrm{e}+08$ & \\
\hline Diretion-3 $\left[1 / \mathrm{m}^{2}\right]$ & $1.056779 \mathrm{e}+08$ & \multirow{2}{*}{ constant } \\
\cline { 1 - 2 } & 236 & \\
\hline Diretion-1 $[1 / \mathrm{m}]$ & 236 & \\
\hline Diretion-2 $[1 / \mathrm{m}]$ & 236 & \\
\hline Diretion-3 $[1 / \mathrm{m}]$ &
\end{tabular}

Viscous Resistance is the effect of surface friction between a particle and a liquid when the particle moves through the liquid. In the context of fluid flow, viscous resistance is energy lost due to the fact that the fluid has to shear to get out of the way of some obstacle, and it doesn't like shearing because it has Viscosity.

Conversely, inertial resistance is energy loss due to that the fluid has to be given kinetic energy to get out of the way of the obstacle, and although in principle this could be recovered and recycled, it commonly ends up being lost through turbulence in the body of fluid. The inertial resistance is proportional to the fluid density times the flow rate. The inertial resistance is significant with gas because flow rates can be high [4].

The significance of inertial resistance is that it tends to be proportional to $\mathrm{v}^{2}$ (whereas viscous resistance is proportional to $\mathrm{v}$ ). Thus it dominates at high flow rates.

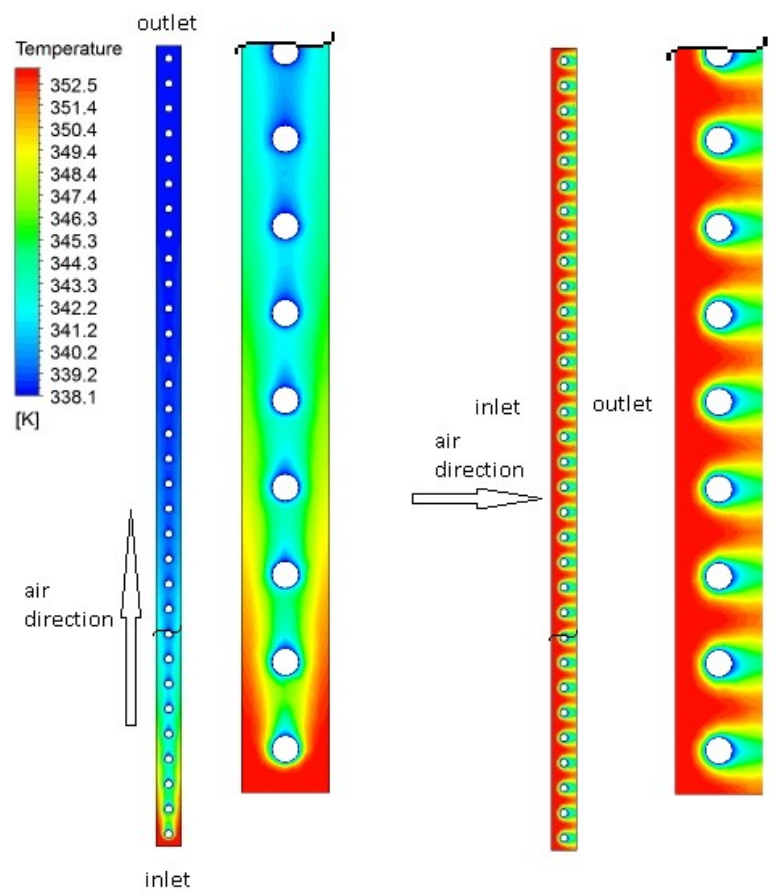

Fig. 4. Temperature results. 


\section{Basic setup for boundary conditions}

The boundary conditions settings were as follows. As the entry area for air was used bottom surface and named as inlet and air velocity entering the intercostal space (in this case porous material) was set at $2.5 \mathrm{~m} / \mathrm{s}$ [5]. Turbulence was set as Intensity with a value of $5 \%$ and a hydraulic diameter of $0.917 \mathrm{~m}$ and the temperature was set to $353.15 \mathrm{~K}$. The exchanger air outlet area was set for upper surface was named as the outlet and set as a pressure-outlet with the same values for the intensity and the hydraulic diameter as the inlet setting. The walls of the Exchanger tubes were set at a temperature of $338.15 \mathrm{~K}$. In second case of exchanger model for inlet and outlet was used from front to back flow of air. All other setup was left as previous.

\section{Results}

Air flow over evaporator heat exchanger was simulated for both cases. Case 1 respond with best result for getting lowest outlet temperature, as shown in Table 4. In Figure 4 is shown flow over exchanger for each case.

Table 4. Temperature results.

\begin{tabular}{|c|c|c|}
\hline \multicolumn{3}{|c|}{ Temperature } \\
\hline case & inlet & outlet \\
\hline 1 & $353.15 \mathrm{~K}$ & $638.15 \mathrm{~K}$ \\
\hline 2 & $353.15 \mathrm{~K}$ & $348.67 \mathrm{~K}$ \\
\hline
\end{tabular}

\section{Conclusion}

The correct functionality of most electronic components is dependent on the operating temperature range. In practice, it means that the components and also the devices must be cooled.

The aim of the work was to determine the best distribution of air over heat exchanger using porous zone model in ANSYS using CFD. The porous zone in the simulation of the flow is preferably used wherever the actual geometry could not be used. For correct adjustment of loss coefficients, it is necessary to perform a test and measure the pressure loss created by the physical part or another model. The Ansys Fluent manual can be used to derive coefficients for porous zone.

The pressure loss simulations were performed for both cases to calculate the coefficients of porosity. Best airflow cooling results have been obtained when the air flows from the bottom of the heat exchanger upwards.

The research is supported by project "Limits of Radiative and Convective Cooling through the Phase Changes of Working Fluid in Loop Thermosyphon", APVV-15-0778.

The research is supported by project: The storage of hydrocarbon gases in hydrate structures as an alternative method of energy accumulation, 063ŽU-4/2018. 


\section{References}

1. R. Lenhard, M. Malcho, J. Jandačka, Heat transfer engineering, 40, 3 (2019)

2. R. Lenhard, J. Jandačka, AIP Conference Proceedings, 1558, 2138 (2013)

3. P. Hrabovský, Š. Papučík, K. Kaduchová, AIP Conference Proceedings, 1745, 020014 (2016)

4. P. Durčanský, Š. Papučík, M. Malcho, AIP Conference Proceedings, 1768, 020028 (2016)

5. J. Raszka, Mechanical Series, LXI, 1996 (2015) 